\title{
Thyroid nodule as a first manifestation of Hodgkin lymphoma-report of two cases and literature review
}

\author{
Ewelina Szczepanek-Parulska', Malgorzata Szkudlarek' ${ }^{1}$ Przemyslaw Majewski², Jan Breborowicz ${ }^{3}$
} and Marek Ruchala ${ }^{1 *}$

\begin{abstract}
Lymphomas account for less than $5 \%$ of thyroid malignant lesions. Vast majority of them are B-cell non-Hodgkin lymphomas (NHL), while Hodgkin lymphoma $(\mathrm{HL})$ is extremely rare. Here we present two cases of $\mathrm{HL}$, at baseline manifesting as a thyroid lesion. First patient, 29-year-old pregnant female, initially suspected for metastatic medullary thyroid cancer, was eventually diagnosed with mixed cellularity type of thyroid HL. Second patient, 22year-old woman with suspicion of advanced thyroid cancer, was in the end diagnosed with an extra-lymphatic classical HL of the thyroid. In both cases, despite repeated fine-needle aspiration biopsy, cytological examination gave inconclusive or misleading results. On histopathological examination, thyroid tumor cells were positive for CD15 and CD30 antigen, which is typical for Reed-Sternberg cells. In the report authors also discuss difficulties in management as well as potential importance of novel methods such as FISH, PCR and other molecular techniques in diagnostics of thyroid lymphomas.
\end{abstract}

Virtual slides: The virtual slide(s) for this article can be found here: http://www.diagnosticpathology.diagnomx.eu/ vs/2896947559559648

Keywords: Thyroid nodule, Hodgkin lymphoma, Fine-needle aspiration biopsy (FNAB), Reed-Sternberg cells

\section{Background}

Hodgkin lymphomas (HL) is a biologically heterogeneous group of neoplasms. The incidence of $\mathrm{HL}$ in European Union is estimated at about 2.2-2.7/100 000 cases per year, constituting $11.7 \%$ of all lymphomas diagnosed in 2006 [1]. The majority of cases is in low-stage disease and presents the nodular sclerosis subtype.

An increase in incidence of extra-nodal lymphomas has been observed over the past two decades [2]. Extra-nodal origin is more common in NHL and may reach 33\% [3]. On the other hand, HL mainly arises in lymph nodes of the neck and mediastinum, while only approximately $5 \%$ develop in extra-nodal sites, including tonsils, nasopharynx, parotid glands, thyroid, parathyroid or nasal antrum, with or without concomitant nodal involvement [4].

\footnotetext{
* Correspondence: mruchala@ump.edu.pl

'Department of Endocrinology, Metabolism and Internal Medicine, Poznan University of Medical Sciences, Poznan, Poland

Full list of author information is available at the end of the article
}

The head and neck is a third place of extra-nodal localization of the lymphomas [5]. Lymphomas account for less than $5 \%$ of malignant lesions diagnosed in the thyroid identified in about two cases per million [6,7]. Vast majority of them are B-cell non-Hodgkin lymphomas (NHL), developing in the course of autoimmune thyroiditis, while HL primarily localized in the thyroid, is a very rare finding $[8,9]$.

Extra-nodal lymphomas (ENL) represent different pathologic, imaging, and clinical features as well as dissimilar prognosis from nodal lymphomas, and should therefore be distinguished [10]. Extra-nodal involvement is much less common in HL compared with NHL. ENL more often spreads by continuity from contiguous nodal disease, while haematogenous spread is rare, occurring in $5 \%-10 \%$ of patients [11].

Hodgkin lymphoma of the thyroid is uncommon and accounts for $0.6-5 \%$ of all thyroid malignancies and 2-7\% of all ENL [12-15]. In vast majority primary thyroid

\section{Biomed Central}


lymphomas are of B-cell origin. Only $1-2 \%$ of thyroid lymphomas derive from T-cell lymphocyte $[12,16]$.

Factors leading to the development of thyroid lymphoma are not fully understood. Some authors attempt to relate a significant prevalence of women with thyroid HL to autoimmune thyroiditis [16]. It is considered, that thyroid lymphoma develops from lymphocytic tissue present in the gland only in case of autoimmune thyroid disease, while normal thyroid gland is devoid of native lymphoid tissue [17]. Hashimoto thyroiditis is detected in $27 \%$ to $100 \%$ of thyroid lymphoma cases [18]. On the other hand, less than $1 \%$ of patients suffering from Hashimoto disease come down with lymphoma $[19,20]$. It is estimated, that a period of 20 to 30 years is needed for lymphoma to develop in case of thyroiditis [17]. In the largest study of patients with HL by Wang et al., 7 out of 21 subjects presented Hashimoto thyroiditis [8].

Among factors, which may play role in the development of thyroid lymphoma, the prolonged antigen stimulation as well as aberrant somatic hypermutation are mentioned [21-24]. Ebstein-Barr virus (EBV) infection is also mentioned as etiological factor, since $20-100 \%$ of systemic $\mathrm{HL}$ is thought to be associated with EBV infection; more likely in mixed cell and lymphocyte depletion types of HL. Moreover, HHV-6 can be detected in $48 \%$ of ReedSternberg (R-S) cells of nodular sclerosis HL and is considered as another factor potentially promoting development of this type of HL [25].

It remains a matter of debate whether thyroid gland in these cases is a primary site of HL origin or a secondary organ involved in the disease [8]. Organ specific HL without concomitant lymph nodes involvement is extremely rare [26]. In our paper we aim to focus on subjects, in whom the diagnosis of HL was made in the course of evaluation of a thyroid lesion and later on involvement of other sites was detected.

Here we present two cases of Hodgkin lymphoma, initially manifesting as thyroid lesions.

\section{Case report}

\section{Patient 1}

In April 2002, 29-year-old pregnant woman was referred for ultrasound examination of the neck due to considerably enlarged cervical lymph nodes detected on palpation. On sonography the packages of lymph nodes with coinciding hypoechogenic ill-defined thyroid lesion were demonstrated, what raised suspicion of advanced thyroid cancer. Patient underwent fine-needle aspiration biopsy (FNAB) of both thyroid lesion and lymph nodes. The result of cytological examination was consistent with suspicion of medullary thyroid cancer. At the time of diagnosis, the patient was 29 weeks pregnant with her first baby. Due to suspicion of metastatic medullary thyroid carcinoma, decision on surgical treatment was made, despite the patient was in the third trimester. The total thyroidectomy with lymphadenectomy was performed, with coordinated care of an anesthesiologist and a gynecologist, constantly monitoring the welfare of both mother and fetus. Perioperative period was uneventful. Post-operative immunohistochemical and histopathological examinations revealed, that previously observed immunostaining for calcitonin was falsely positive in lacunar cells and lymphocytes. Thyroid tumor cells expressed antigen CD15 and CD30, which is typical for R-S cells, being a marker of HL. Thus, final diagnosis of mixed cellularity (MC) type $\mathrm{HL}$ of the thyroid was established (Figure 1). Only retrospective verification of the specimen obtained during preoperative FNAB, revealed the presence of R-S cell (Figure 2). Consulting hematologist decided to postpone chemotherapy for the time after delivery. In the 36th week of pregnancy, the symptoms of preterm labor occurred and the patient delivered a healthy boy by caesarean section. Three weeks later the patient was admitted to the department of hematology, where thorough clinical evaluation, bone marrow biopsy and imaging studies were performed to establish the advancement of the disease. The patient presented involvement of cervical and thoracic lymph nodes, splenomegaly and clinical symptoms (fever $>38^{\circ} \mathrm{C}$ and sweating), hence IVB stage of $\mathrm{HL}$ according to Ann Arbor classification was diagnosed. She received 8 courses of ABVD (Adriamycin, Bleomycin, Vinblastine, Dacarbazine) chemotherapy and reached remission. During 10-year follow-up period, no relapse of lymphoma was detected. Four years following the therapy, the patient got pregnant and gave birth to healthy female twins. She is still followed up in an endocrine outpatient clinic and her hormonal balance is maintained with $100 \mu \mathrm{g}$ of L-thyroxin.

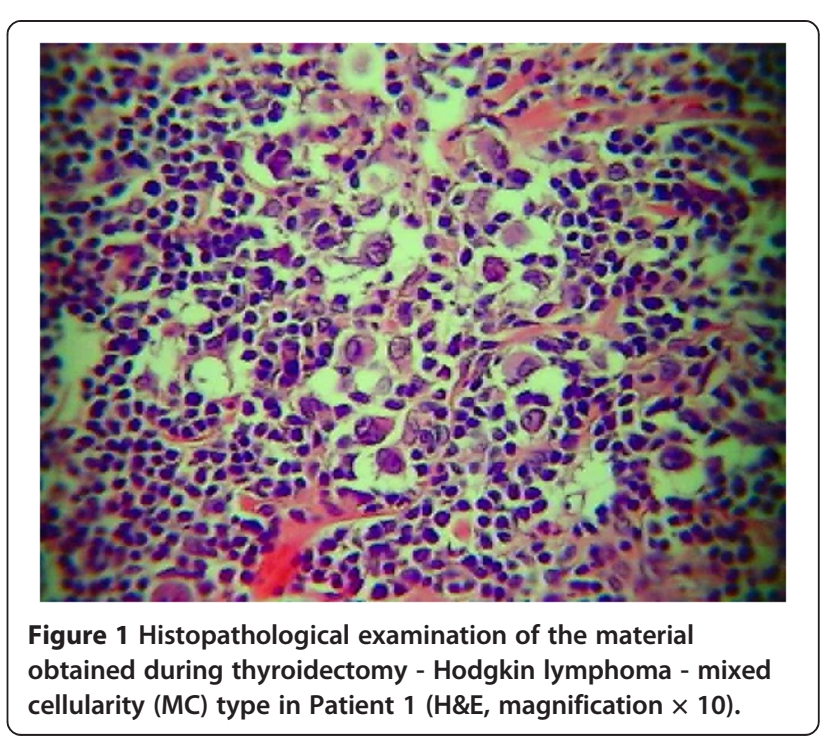




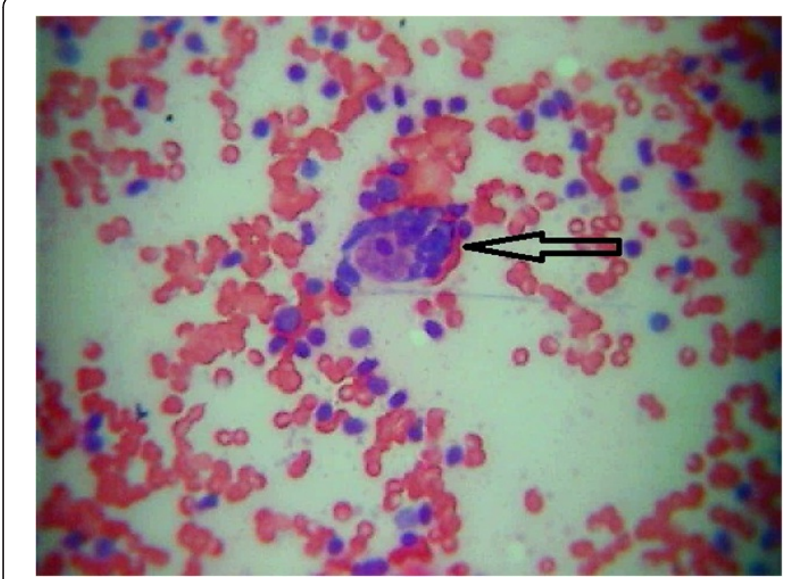

Figure 2 Retrospective verification of cytological specimen obtained preoperatively during fine-needle aspiration biopsy of the thyroid in the Patient 1. An arrow indicates Reed-Sternberg cell, presence of which might provide preoperative diagnosis of Hodgkin lymphoma (H\&E, magnification $\times 400)$.

\section{Patient 2}

23-year-old woman came to a laryngologist with painless bilateral enlargement of neck lymph nodes and hoarseness. Despite prescribed antibiotic therapy, symptoms persisted, thus ultrasound examination of the neck was performed, which demonstrated thyroid lesion with concomitant involvement of lymph nodes. Subsequently the patient was referred to the endocrinology outpatient clinic with suspicion of advanced thyroid cancer in September 2008. On thyroid ultrasound examination, a large $(32 \times 30 \mathrm{~mm})$, hypoechogenic lesion, localized at the border between left thyroid lobe and isthmus, was visualized. Unilaterally, package of enlarged, round and hypoechogenic lymph nodes of size $20 \times 12 \mathrm{~mm}$ was found, suggesting metastatic lesions. The trachea was displaced to the right side. On thyroid scintiscan, a large cold nodule was found and its localization corresponded to the lesion revealed during ultrasonography. The chest $\mathrm{X}$-ray disclosed the enlargement of the upper mediastinum (to $70 \mathrm{~mm}$ ). There was no past history of thyroid or hematologic disease. Her family history was noncontributory. At the time of diagnosis the patient was euthyroid and thyroid autoantibodies were negative. Other laboratory tests revealed accelerated ESR and increased concentration of white blood cells with depletion of lymphocytes and eosinophils. Thyroid and lymph nodes FNAB was performed three times. The cytological examination of initial two specimens gave non-diagnostic result due to too small amount of cells obtained in the specimens. Eventually, the third biopsy allowed to detect suspected cells of undetermined origin. The clinical picture, together with results of imaging studies and cytological examination, prompted us to refer the patient for immediate total thyroidectomy with lymphadenecto- my. Immunohistochemical studies were performed and showed the tumor cells expressing CD30+, CD15+, Ki67+. Tumor cells were negative for D3-, CD20-, CKAE1/3, EBV-LMP1. Thus a final diagnosis of extra-lymphatic classical HL (nodular sclerosis subtype) of the thyroid was made (Figures 3 and 4).

The patient was subsequently referred to the department of hematology. On the base of clinical picture, imaging examinations and bone marrow assessment, she was classified for stage IIE of disease in Ann Arbor classification. The patient was subjected to combined chemotherapy (12 cycles of ABVD) and radiotherapy, starting from December 2008. The following imaging studies, including chest X-ray and positron emission tomography were performed to confirm remission status and did not reveal any pathological changes. The patients observation period has now reached four years and is uneventful. She continues to be followed-up in an endocrinology outpatient clinic and remains both clinically and biochemically euthyroid on substitutive $125 \mu \mathrm{g}$ dose of L-thyroxin.

\section{Discussion}

Neoplasms diagnosed in the thyroid gland are usually primary thyroid cancers, while lymphomas account for less than $5 \%$ of malignant lesions diagnosed in the thyroid. Vast majority of them are B-cell non-Hodgkin lymphomas (NHL), developing in the course of autoimmune thyroiditis, while Hodgkin lymphoma (HL), primarily localized in the thyroid, is a very rare finding [12-14]. However, in differential diagnosis also rarely occurring tumours of this localization need to be involved [27-31]. The thyroid gland constitutes an uncommon site for metastatic changes from various primary sites. Thyroid metastases are encountered in $2 \%$ to $24 \%$ of the

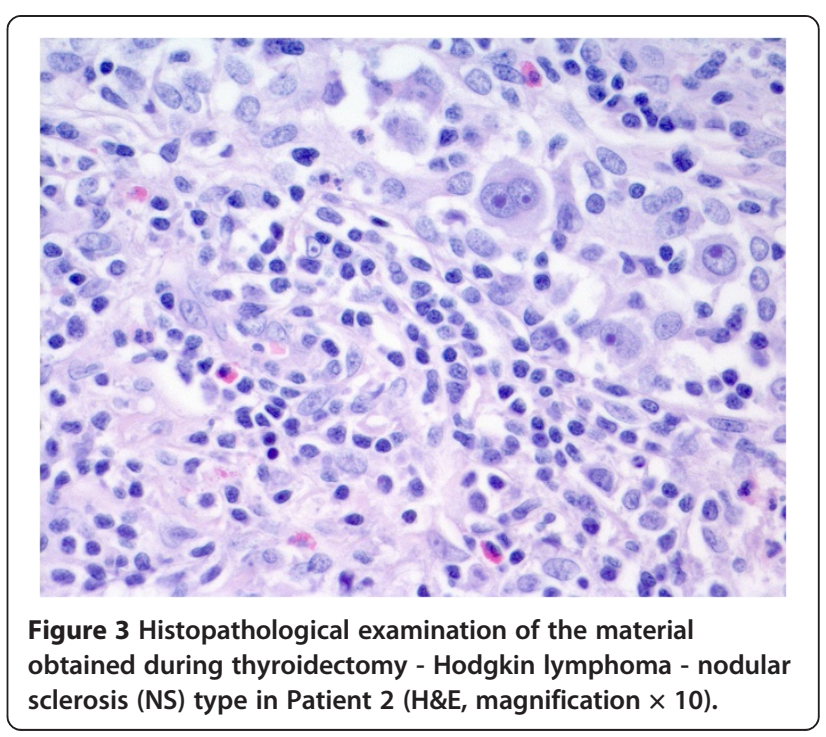




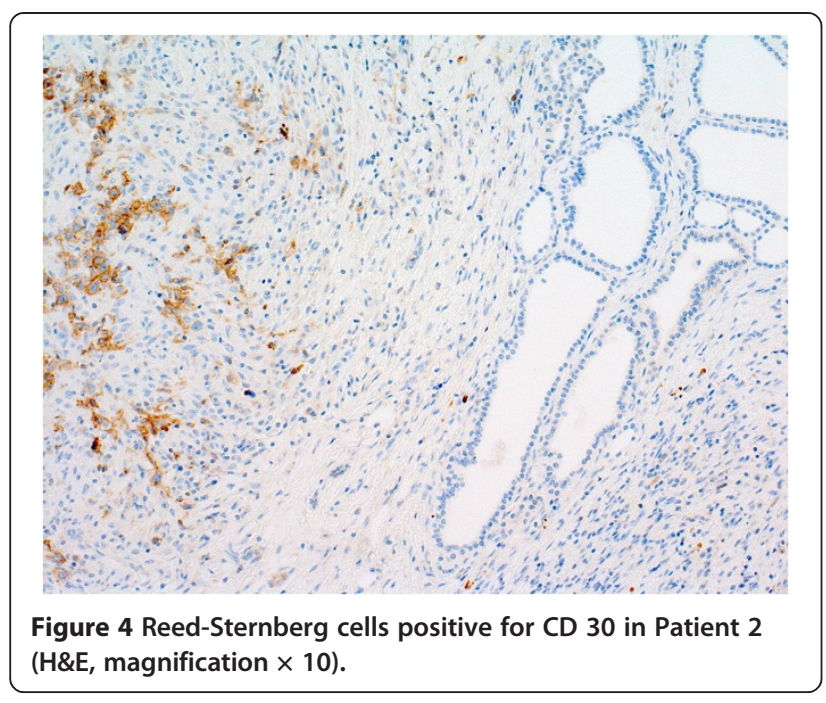

patients with malignant neoplasm [28]. Differential diagnosis of thyroid lesions should also comprise other uncommon primary thyroid tumors. Leiomyosarcomas of the thyroid account for $6 \%$ of the all head and neck tumors, with 18 cases described so far in the world literature [29]. Primary squamous cell carcinoma (SCC) of the thyroid is also an extremely rare entity, observed in less than $1 \%$ of all thyroid malignancies [30]. Vascular lesions include benign tumors such as hemangiomas and malignant ones including angiosarcomas or undifferentiated angiosarcomatoid carcinomas [31].

Our extensive literature search revealed thirty seven cases of HL located in the thyroid gland reported to date. In patients with thyroid HL women predominate and constitute about $75-80 \%$ of reported patients [4,32], while systemic HL has an equal male to female ratio. In the paper describing the largest series of subjects with thyroid HL by Wang et al., an average age of a patient with HL of the thyroid gland was 42 (with range from 18 to 64) and was lower than for NHL (7th decade) [8]. About two thirds of patients suffering from thyroid HL were younger than 45 years old [33]. It is consistent with what we learned from our patients, who were diagnosed even below the age of thirty.

As we mentioned above, autoimmune thyroiditis is one of the factors linked with development of lymphomas. Our two patients with thyroid HL presented neither laboratory nor cytological features of thyroid inflammation. Thyroid HL in over $80 \%$ of patients manifests as a rapidly enlarging unilateral or bilateral neck mass. Other clinical symptoms include: hoarseness (35\%), dyspnea (65\%) and dysphagia (53\%) [28]. HL of the thyroid may present as diffuse involvement of the gland or a focal lesion [29]. Both our patients presented enlargement of neck lymph nodes and the second one also has been complaining about hoarseness. Similarly to our patients, on physical examination in most cases thyroid tumor tends to be firm to hard upon palpation [30]. Vast majority of formerly reported patients with HL presented concomitant neck lymph nodes involvement at the time of diagnosis, but the presence of B-symptoms, including inter alia fever and sweating occurring in one of our patients, at the same time is relatively rare (33\%) [16]. B-symptoms may develop in the course of lymphoma and are usually associated with systemic involvement and constitute a marker of negative prognosis. These include temperature $>38^{\circ} \mathrm{C}\left(>100.4^{\circ} \mathrm{F}\right)$ for three consecutive days, weight loss exceeding $10 \%$ of body weight in 6 months and drenching night sweats.

Patients with thyroid HL are mostly euthyroid or less often hypothyroid (30-40\%) at the time of diagnosis [34]. Both our patients presented normal thyroid function. On scintiscan HL localized in the thyroid presents as a cold nodule, while ultrasound examination reveals diffused or focal thyroid enlargement, mimicking thyroiditis or primary thyroid lesion [8]. In case of the first patient, scintiscan was contraindicated because of pregnancy. A large cold nodule was found on thyroid scintiscan of the second patient. The involved lymph nodes are homogeneous, variable in size and might display necrosis and calcifications [4]. On ultrasound examination, enlarged lymph nodes were found in both described cases. However, despite increased size and formation of packages, no other suspected features of lymph nodes were demonstrated.

The difficulty in diagnosis poses the fact, that if the personal history is negative for hematologic diseases, the thyroid lymphoma is rarely suspected. Diagnosis of lymphoma should be considered when dealing with rapidly enlarging goitre. The FNAB constitutes the initial examination used for evaluation of thyroid lesion. Its role is limited but the procedure is necessary for both immunocytochemical studies and flow cytometry. Primary thyroid HL should be suspected when the specimen consists of lymphocytes, but carcinoma cannot be excluded. The reports on the efficacy of FNAB in diagnostics of thyroid lymphomas provide diverse results. According to different studies, $50-80 \%$ of cases of thyroid lymphomas is revealed on the basis of FNAB results [7,13,35-38]. However, Gupta et al. reported that in nine out of ten cases, a diagnosis of NHL was made on the base of FNAB [13]. Only in one case, in a patient presenting diffuse swelling, cytology demonstrated a polymorphic infiltrate consistent with reactive hyperplasia and the diagnosis of lymphoma was missed [13]. In the study by Dedecjus et al., the proper diagnosis of thyroid lymphoma was made in less than $50 \%$ of cases in USguided FNAB, while in other study by Seningen et al., the FNAB characterized with very high specificity and positive predictive value at the level of $99.6 \%$ and $88.9 \%$, 
respectively $[3,39]$. In case of a primary thyroid NHL, diagnosis of large cell type lymphoma is simple on FNAB due to build of large cells, lack of cellular cohesion and lymphoglandular bodies in the background [13]. On the contrary, diagnosis of MALT- lymphomas basing on cytology is difficult due to heterogeneous appearance of the neoplastic infiltrate [40].

Differentiation of primary thyroid lymphoma from thyroid cancer and Hashimoto thyroiditis may produce a diagnostic dilemma. Low accuracy of FNAB comes out of hypocellular samples, small population of R-S cells, marked fibrosis and sclerosis, resemblance between the R-S cells and inflammatory cells and, finally, very rare incidence of thyroid HL [8]. Immunocytochemistry should be used to confirm the suspicion of lymphoma [41]. Small biopsy probes may lead to diagnosis of thyroiditis instead of lymphoma, due to presence of neutrophils, abscess or necrosis [42]. It remains a challenge to differentiate between benign and malignant lymphoid infiltrate [19]. FNAB constitutes a helpful initial diagnostic device to establish the preliminary diagnosis, however is not sufficient for the final one, because the evaluation of lymph node architecture is extremely important $[43,44]$. What is more, in HL the tumour cells represent the minority of the cellular population, where normal reactive lymphocytes, eosinophils, and histiocytes predominate. Hence, cytological specimen obtained during FNAB may not contain the R-S cells, indispensable for adequate diagnosis [44]. Lymphomas may differ from Hashimoto thyroiditis with the abundance of lymphoid tissue and a high proportion of intermediate centrocyte-like cells, especially in low-grade NHL. A sampling error and coexistence of Hashimoto thyroiditis and lymphoma might cause false-negative results [40].

The diagnostic accuracy of FNAB of lymph node is evaluated from 30 to $92 \%$. The main limitations are fibrosis and abundant benign surroundings $[42,45]$. It is reported in the literature that a single-tube flow cytometry can be used in screening of classic HL in tissue body sections or FNAB specimens with $88 \%$ sensitivity and even $100 \%$ specificity $[42,46]$. Other corroborative methods include tissue biopsy and surgery.

Contemporary development in diagnostics allow to increase the diagnostic accuracy of cytological examination in lymphomas. Immunocytochemistry allows for confirmation of the lymphoid origin of the cells and their B or T-lineage [13]. Flow cytometry is a well-adapted method to establish the immunophenotype in FNAB specimens $[19,47]$. In case of lymph nodes, flow cytometry characterizes with high sensitivity and specify, ranging from 94 to $100 \%$ [47-50]. However, in flow cytometry-based diagnosis of the thyroid gland lesions, elevated $\kappa: \lambda$ ratios have been observed in many case of thyroiditis, what can produce a diagnostic dilemma [51].
Ochs et. al stress that genetic testing, including polymerase chain reaction (PCR) and florescence in situ hybridization (FISH) is feasible and useful tool in diagnosis of thyroid lymphomas [19]. Identification of genetic abnormalities can be critical to the diagnosis of lymphoma, especially this of unusual site of origin like lymphomas of thyroid gland [19]. Endocrinologists frequently have to make a decision solely on the basis of FNAB hence the use of molecular testing in limited material obtained during FNAB is very helpful to establish diagnosis prior to invasive procedures [19]. PCR-based methods constitute important diagnostic method in cases when flow cytometry does not allow to reveal clonality of the cells. Clonality testing can be applied for indicating the relationship between sites in multifocal disease [19]. R-S cells account for only $0.1-1 \%$ of the cells in material obtained during FNAB [52]. Molecular techniques targeting these cells provide some information on cytogenetic aberrations in HL [52]. However, immunoglobulin heavy chain genes should be interpreted with attention due to frequency of monoclonal rearrangement in thyroiditis [53].

Genomic gains in chromosom arm 2p, including REL gene and gains in $9 \mathrm{p}$ are present in 30 to $50 \%$ of classic HL [54-57]. Chromosomal breakpoints affecting immunoglobulin loci are recurrent in B-cell lymphomas, but also classical HL. In about $17 \%$ of R-S cells, MartinSubero et al. observed breakpoints in IGH, IGL or IGK locus [52,57].

Other molecular cytogenic technics useful in diagnostic process of HL apart from FISH and PCR include comparative genomic hybridization $(\mathrm{CGH})$ from microdissected R-S cells, fluorescence immunophenotyping and interphase cytogenetics (FICTION) as a tool for the investigation of neoplasms [52].

In case of our two patients FNAB failed to bring the preoperative diagnosis of HL. Unfortunately, none of the above described advanced techniques supporting cytological examination were at the moment of evaluation of the described patients a part of routine diagnosis at our department. In Patient 1, non-specific staining for calcitonin resulted in misdiagnosing medullary thyroid cancer, and only during the retrospective re-evaluation of the cytological material obtained during FNAB, R-S cell was identified. Incidence of calcitonin-containing cells in thyroid lymphoma and in Hashimoto thyroiditis was already described by Baschieri et al. [58]. C cell hyperplasia is present frequently in lymphomas and shows positivity for calcitonin. Hyperplastic $C$ cells are not observed in Hashimoto thyroiditis. Hence, an increase in the $\mathrm{C}$ cell number might be a marker of thyroid lymphoma [58].

In Patient 2, the repeated FNAB did not allow to obtain the number of cells high enough to establish diagnosis. Hence, without clinician's suggestion and experience of 
pathologists, possibility of HL diagnosis in the thyroid gland is limited.

Final pathological diagnosis should be made from surgical specimen or excisional lymph node biopsy and should be based on WHO classification [25,59]. One of the basis of histopathological diagnosis of HL is the identification of the presence of R-S cells. These are large mutated cells, derived from B lymphocytes, presenting with an amphophylic cytoplasm and multiple or a bilobed nucleus, eosinophilic inclusion-mimicking nucleoli, devoid of typical B-cell markers such as CD20 and CD79a. Their characteristic immunophenotype is of crucial importance in diagnosis of HL. A CD 30 antigen is typical for R-S cells, while CD 15, an antigen normally expressed in monocytes and granulocytes, but not in lymphocytes, is present at R-S cells in 75-85\%, independent of the type of HL $[60,61]$.

Classical HL, which constitutes about $95 \%$ of all HL cases, can be divided into nodular sclerosis, mixed cellularity, lymphocyte-rich and lymphocyte depleted subtypes [25]. Staging is estimated according to the Ann Arbor system and it determines prognosis and validity of radiotherapy [59]. Most patients present stage I or II of the disease and the nodular sclerosis subtype [8]. There were only two cases of mixed cellular subtype of HL involving the thyroid reported so far in the literature and to our knowledge, one of our patients would be a third case $[8,62]$.

The literature search reveals that surgical removal of the thyroid affected with HL does not influence the prognosis $[22,44]$. HL responds quickly to chemotherapy and radiotherapy, while surgical risk is considered unnecessary $[22,32]$. However, excision of the lesion can be of importance in cases with acute airway obstruction [34]. Preoperative diagnosis is not always established, hence, due to similar clinical picture of hypoechogenic lesion of the thyroid, presenting as cold nodule in the scintiscan, the patient is referred for thyroid surgery with suspicion of primary thyroid cancer, as it was in case of both our patients. The nodal involvement additionally suggests metastatic disease. Hence, if the presurgical diagnosis of HL is reached, the operation is not recommended. However, in both our cases, cytological examinations was not conclusive, hence surgery and histopathological examination was the only way to determine the diagnosis.

With appropriate therapy, primary thyroid HL is associated with favourable prognosis. Nowadays, chemotherapy (ABVD) and 30 Gy radiotherapy is the treatment of choice in primary thyroid lymphoma $[25,63]$. The final outcome depends on the histological type and stage of the disease at presentation. The survival is significantly greater for HL than for NHL [16]. It was determined, that both high value of ESR (over $50 \mathrm{~mm} / \mathrm{h}$ without systemic symptoms) and extra-nodal involvement independently constitute important pretreatment prognostic factors in subjects with HL $[2,64]$. One of our patients presented markers of unfavourable prognosis such as ESR $71 \mathrm{~mm} / \mathrm{h}$ and both had extranodal localization of the lymphoma. However, at the moment of publication, both patients were in remission for ten and four years, respectively.

\section{Conclusions}

To conclude, despite its rarity, Hodgkin lymphoma ought to be considered in differential diagnosis of thyroid lesions. An appropriate preoperative diagnosis prevents from unnecessary total thyroidectomy. Hodgkin lymphoma that initially presents as a thyroid mass, treated with combined modality therapy has favourable outcome.

\section{Consent}

Written informed consent was obtained from the patient for publication of this Case Report and any accompanying images. A copy of the written consent is available for review by the Editor-in-Chief of this journal.

Competing interests
The authors declare that they have no competing interests.

\section{Authors' contributions}

ESP preparated manuscipt, performed the literature review. MS preparated manuscipt, performed the literature review. PM performed histopathological examinations and documentation, acquired photomicrographs. JB gave the final histopathological diagnosis and prepared the documentation. MR participated in patient management and corrected the manuscript and approved of the final version of the manuscript. All authors read and approved the final manuscript.

\section{Author details}

'Department of Endocrinology, Metabolism and Internal Medicine, Poznan University of Medical Sciences, Poznan, Poland. ${ }^{2}$ Department of Clinical Pathology, Poznan University of Medical Sciences, Poznan, Poland.

${ }^{3}$ Department of Oncology, Poznan University of Medical Sciences, Poznan, Poland.

Received: 4 April 2013 Accepted: 30 June 2013

Published: 15 July 2013

\section{References}

1. Mani H, Jaffe ES: Hodgkin lymphoma: an update on its biology with new insights into classification. Clin Lymphoma Myeloma 2009, 9(3):206-216.

2. llica AT, Kocacelebi K, Savas R, Ayan A: Imaging of extranodal lymphoma with PET/CT. Clin Nucl Med 2011, 36(10):e127-e138.

3. Dedecjus M, Kedzierska A, Kozak J, Kordek R, Brzezinski J: A rare case of Hodkin's lymphoma of the mediastinum imitating retrosternal goiter-retrospective analysis of the diagnostic process. Pol Przegl Chir 2012, 84(7):363-366.

4. Weber AL, Rahemtullah A, Ferry JA: Hodgkin and non-Hodgkin lymphoma of the head and neck: clinical, pathologic, and imaging evaluation. Neuroimaging Clin N Am 2003, 13(3):371-392.

5. Hart S, Horsman JM, Radstone CR, Hancock H, Goepel JR, Hancock BW: Localised extranodal lymphoma of the head and neck: the Sheffield Lymphoma Group experience (1971-2000). Clin Oncol (R Coll Radiol) 2004, 16(3):186-192.

6. Graff-Baker A, Sosa JA, Roman SA: Primary thyroid lymphoma: a review of recent developments in diagnosis and histology-driven treatment. Curr Opin Oncol 2010, 22(1):17-22.

7. Matsuzuka F, Miyauchi A, Katayama S, Narabayashi I, Ikeda H, Kuma K, Sugawara M: Clinical aspects of primary thyroid lymphoma: diagnosis and treatment based on our experience of 119 cases. Thyroid 1993, 3(2):93-99. 
8. Wang SA, Rahemtullah A, Faquin WC, Roepke J, Harris NL, Hasserjian RP: Hodgkin's lymphoma of the thyroid: a clinicopathologic study of five cases and review of the literature. Mod Pathol 2005, 18(12):1577-1584.

9. Ruchala M, Szczepanek E: Thyroid ultrasound - a piece of cake? Endokrynol Pol 2010, 61(3):330-344.

10. Freeman C, Berg JW, Cutler SJ: Occurrence and prognosis of extranodal lymphomas. Cancer 1972, 29(1):252-260.

11. Even-Sapir E, Lievshitz G, Perry C, Herishanu Y, Lerman H, Metser U: Fluorine-18 fluorodeoxyglucose PET/CT patterns of extranodal involvement in patients with Non-Hodgkin lymphoma and Hodgkin's disease. Radiol Clin North Am 2007, 45(4):697-709. vii.

12. Forconi F, Bocchia M, Marconcini S, Bigazzi C, Milani M, Fraternali-Orcioni G, Lauria F: CD30 positive (non-anaplastic) peripheral T-cell lymphoma of the thyroid gland. Haematologica 1999, 84(10):946-948.

13. Gupta N, Nijhawan R, Srinivasan R, Rajwanshi A, Dutta P, Bhansaliy A Sharma SC: Fine needle aspiration cytology of primary thyroid lymphoma: a report of ten cases. Cytojournal 2005, 2:21

14. Derringer GA, Thompson LD, Frommelt RA, Bijwaard KE, Heffess CS, Abbondanzo SL: Malignant lymphoma of the thyroid gland: a clinicopathologic study of 108 cases. Am J Surg Pathol 2000, 24(5):623-639.

15. Aozasa K, Tsujimoto M, Sakurai M, Honda M, Yamashita K, Hanada M, Sugimoto A: Non-Hodgkin's lymphomas in Osaka, Japan. Eur J Cancer Clin Oncol 1985, 21(4):487-492.

16. Enrique A, Quesada JL, Lorente J, Lopez D: Hodgkin and Non-Hodgkin lymphomas in otorhinolaryngology. Acta Otorrinolaringol Esp 2004, 55(8):387-389.

17. Pedersen RK, Pedersen NT: Primary non-Hodgkin's lymphoma of the thyroid gland: a population based study. Histopathology 1996, 28(1):25-32.

18. Vianna DM, Curioni OA, Franca $L$, de Paiva DL, Pompeu BF, Dedivitis RA, Rapoport A: The histological rarity of thyroid cancer. Braz J Otorhinolaryngol 2012, 78(4):48-51.

19. Ochs RC, Bagg A: Molecular genetic characterization of lymphoma: application to cytology diagnosis. Diagn Cytopathol 2012, 40(6):542-555.

20. Watanabe N, Noh JY, Narimatsu H, Takeuchi K, Yamaguchi T, Kameyama K, Kobayashi K, Kami M, Kubo A, Kunii Y, Shimizu T, Mukasa K, Otsuka F, Miyara A, Minagawa A, Ito K: Clinicopathological features of 171 cases of primary thyroid lymphoma: a long-term study involving 24553 patients with Hashimoto's disease. Br J Haematol 2011, 153(2):236-243.

21. Liso A, Capello D, Marafioti T, Tiacci E, Cerri M, Distler V, Paulli M, Carbone A Delsol G, Campo E, Pileri S, Pasqualucci L, Gaidano G, Falini B: Aberrant somatic hypermutation in tumor cells of nodular-lymphocyte-predominant and classic Hodgkin lymphoma. Blood 2006, 108(3):1013-1020.

22. Thieblemont C, Mayer A, Dumontet C, Barbier $Y$, Callet-Bauchu E, Felman $P$, Berger F, Ducottet X, Martin C, Salles G, Orgiazzi J, Coiffier B: Primary thyroid lymphoma is a heterogeneous disease. J Clin Endocrinol Metab 2002, 87(1):105-111.

23. Nix P, Nicolaides A, Coatesworth AP: Thyroid cancer review 2: management of differentiated thyroid cancers. Int J Clin Pract 2005, 59(12):1459-1463.

24. Anderson T, Chabner BA, Young RC, Berard CW, Garvin AJ, Simon RM, DeVita VT Jr: Malignant lymphoma. 1. The histology and staging of 473 patients at the National Cancer Institute. Cancer 1982, 50(12):2699-2707.

25. Engert A, Eichenauer DA, Dreyling M, Group EGW: Hodgkin's lymphoma: ESMO clinical recommendations for diagnosis, treatment and follow-up. Ann Oncol 2009, 20(Suppl 4):108-109.

26. Li Y, Wang XB, Tian XY, Li B, Li Z: Unusual primary osseous Hodgkin lymphoma in rib with associated soft tissue mass: a case report and review of literature. Diagn Pathol 2012, 7:64

27. Ma Y, Li Q, Cui W, Miao N, Liu X, Zhang W, Zhang C, Wang J: Expression of c-Jun, p73, Casp9, and N-ras in thymic epithelial tumors: relationship with the current WHO classification systems. Diagn Pathol 2012, 7:120.

28. Hafez MT, Hegazy MA, Abd Elwahab K, Arafa M, Abdou I, Refky B: Metastatic rhabdomyosarcoma of the thyroid gland, a case report. Head Neck Oncol 2012, 4:27.

29. Amal B, El Fatemi H, Souaf I, Moumna K, Affaf A: A rare primary tumor of the thyroid gland: report a new case of leiomyosarcoma and literature review. Diagn Pathol 2013, 8:36

30. Shrestha M, Sridhara SK, Leo LJ, Coppit GL III, Ehrhardt NM: Primary squamous cell carcinoma of the thyroid gland: a case report and review. Head Neck 2012. doi:10.1002/hed.23152 [Epub ahead of print].

31. Petronella P, Scorzelli M, Luise R, lannaci G, Sapere P, Ferretti M, Costanzo RM, Freda F, Canonico S, Rossiello R: Primary thyroid angiosarcoma: an unusual localization. World J Surg Oncol 2012, 10:73.
32. Diklic A, Zivaljevic V, Paunovic I, Krgovic K, Zivic R, Kazic M, Kalezic N, Tatic S, Havelka M, Bozic V: Lymphoma and other rare malignant tumors of the thyroid. Acta Chir lugos/ 2003, 50(3):141-146.

33. Graff-Baker A, Roman SA, Thomas DC, Udelsman R, Sosa JA: Prognosis of primary thyroid lymphoma: demographic, clinical, and pathologic predictors of survival in 1,408 cases. Surgery 2009 146(6):1105-1115

34. Sarinah B, Hisham AN: Primary lymphoma of the thyroid: diagnostic and therapeutic considerations. Asian J Surg 2010, 33(1):20-24.

35. Matsuda $\mathrm{M}$, Sone $\mathrm{H}$, Koyama $\mathrm{H}$, Ishiguro S: Fine-needle aspiration cytology of malignant lymphoma of the thyroid. Diagn Cytopathol 1987, 3(3):244-249.

36. Skarsgard ED, Connors JM, Robins RE: A current analysis of primary lymphoma of the thyroid. Arch Surg 1991, 126(10):1199-1203. discussion 1203-4.

37. Das DK, Gupta SK, Francis IM, Ahmed MS: Fine-needle aspiration cytology diagnosis of non-Hodgkin lymphoma of thyroid: a report of four cases. Diagn Cytopathol 1993, 9(6):639-645.

38. Klyachkin ML, Schwartz RW, Cibull M, Munn RK, Regine WF, Kenady DE, McGrath PC, Sloan DA: Thyroid lymphoma: is there a role for surgery? Am Surg 1998, 64(3):234-238.

39. Seningen $J$, Nassar A, Henry MR: Correlation of thyroid nodule fineneedle aspiration cytology with corresponding histology at Mayo Clinic, 2001-2007: an institutional experience of 1,945 cases. Diagn Cytopathol 2012, 40(Suppl 1):E27-E32.

40. Sangalli G, Serio G, Zampatti C, Lomuscio G, Colombo L: Fine needle aspiration cytology of primary lymphoma of the thyroid: a report of 17 cases. Cytopathology 2001, 12(4):257-263.

41. Hwang YC, Kim TY, Kim WB, Shong YK, Yi KH, Shong M, Jo YS, Kim WS, Chung $\mathrm{JH}$ : Clinical characteristics of primary thyroid lymphoma in Koreans. Endocr J 2009, 56(3):399-405.

42. Listinsky CM: A practical approach to the diagnosis of Hodgkin lymphoma. Am J Clin Pathol 2002, 117(Suppl):S76-S94.

43. Aozasa K, Inoue A, Tajima K, Miyauchi A, Matsuzuka F, Kuma K: Malignant lymphomas of the thyroid gland. Analysis of 79 patients with emphasis on histologic prognostic factors. Cancer 1986, 58(1):100-104.

44. Ansell SM: Hodgkin lymphoma: 2012 update on diagnosis, riskstratification, and management. Am J Hematol 2012, 87(12):1096-1103.

45. Catrina Reading F, Schlette EJ, Stewart JM, Keating MJ, Katz RL, Caraway NP Fine-needle aspiration biopsy findings in patients with small lymphocytic lymphoma transformed to hodgkin lymphoma. Am J Clin Pathol 2007, 128(4):571-578.

46. Fromm JR, Thomas A, Wood BL: Flow cytometry can diagnose classical hodgkin lymphoma in lymph nodes with high sensitivity and specificity. Am J Clin Pathol 2009, 131(3):322-332

47. Schmid S, Tinguely M, Cione $\mathrm{P}$, Moch $\mathrm{H}$, Bode B: Flow cytometry as an accurate tool to complement fine needle aspiration cytology in the diagnosis of low grade malignant lymphomas. Cytopathology 2011, 22(6):397-406

48. Bangerter M, Brudler $O$, Heinrich B, Griesshamnuer M: Fine needle aspiration cytology and flow cytometry in the diagnosis and subclassification of non-Hodgkin's lymphoma based on the World Health Organization classification. Acta Cytol 2007, 51(3):390-398.

49. Demurtas A, Accinelli G, Pacchioni D, Godio L, Novero D, Bussolati G, Palestro G, Papotti M, Stacchini A: Utility of flow cytometry immunophenotyping in fine-needle aspirate cytologic diagnosis of non-Hodgkin lymphoma: a series of 252 cases and review of the literature. Appl Immunohistochem Mol Morphol 2010, 18(4):311-322.

50. Liu K, Stern RC, Rogers RT, Dodd LG, Mann KP: Diagnosis of hematopoietic processes by fine-needle aspiration in conjunction with flow cytometry: a review of 127 cases. Diagn Cytopathol 2001, 24(1):1-10.

51. Chen HI, Akpolat I, Mody DR, Lopez-Terrada D, De Leon AP, Luo Y, Jorgensen J, Schwartz MR, Chang CC: Restricted kappa/lambda light chain ratio by flow cytometry in germinal center $B$ cells in Hashimoto thyroiditis. Am J Clin Pathol 2006, 125(1):42-48

52. Martin-Subero Jl, Klapper W, Sotnikova A, Callet-Bauchu E, Harder L, Bastard C, Schmitz R, Grohmann S, Hoppner J, Riemke J, Barth TF, Berger F, Bernd HW, Claviez A, Gesk S, Frank GA, Kaplanskaya IB, Moller P, Parwaresch RM, Rudiger T, Stein H, Kuppers R, Hansmann ML, Siebert R, Deutsche Krebshilfe Network Project Molecular Mechanisms in Malignant L: Chromosomal breakpoints affecting immunoglobulin loci are recurrent in Hodgkin and Reed-Sternberg cells of classical Hodgkin lymphoma. Cancer Res 2006, 66(21):10332-10338 
53. Zeppa P, Cozzolino I, Peluso AL, Troncone G, Lucariello A, Picardi M, Carella C, Pane F, Vetrani A, Palombini L: Cytologic, flow cytometry, and molecular assessment of lymphoid infiltrate in fine-needle cytology samples of Hashimoto thyroiditis. Cancer 2009, 117(3):174-184.

54. Joos S, Kupper M, Ohl S, von Bonin F, Mechtersheimer G, Bentz M, Marynen P, Moller P, Pfreundschuh M, Trumper L, Lichter P: Genomic imbalances including amplification of the tyrosine kinase gene JAK2 in CD30+ Hodgkin cells. Cancer Res 2000, 60(3):549-552.

55. Joos S, Menz CK, Wrobel G, Siebert R, Gesk S, Ohl S, Mechtersheimer G, Trumper L, Moller P, Lichter P, Barth TF: Classical Hodgkin lymphoma is characterized by recurrent copy number gains of the short arm of chromosome 2. Blood 2002, 99(4):1381-1387.

56. Joos S, Granzow M, Holtgreve-Grez H, Siebert R, Harder L, Martin-Subero Jl, Wolf J, Adamowicz M, Barth TF, Lichter P, Jauch A: Hodgkin's lymphoma cell lines are characterized by frequent aberrations on chromosomes $2 p$ and 9p including REL and JAK2. Int J Cancer 2003, 103(4):489-495.

57. Martin-Subero Jl, Gesk S, Harder L, Sonoki T, Tucker PW, Schlegelberger B, Grote W, Novo FJ, Calasanz MJ, Hansmann ML, Dyer MJ, Siebert R: Recurrent involvement of the REL and BCL11A loci in classical Hodgkin lymphoma. Blood 2002, 99(4):1474-1477.

58. Baschieri L, Castagna M, Fierabracci A, Antonelli A, Del Guerra P, Squartini F: Distribution of calcitonin- and somatostatin-containing cells in thyroid lymphoma and in Hashimoto's thyroiditis. Appl Pathol 1989, 7(2):99-104.

59. Linch DC, Gosden RG, Tulandi T, Tan SL, Hancock SL: Hodgkin's lymphoma: choice of therapy and late complications. Hematology Am Soc Hematol Educ Program 2000, 2000(no. 1):205-221. ASH Education Book January 1, 2000.

60. Kuppers R, Engert A, Hansmann ML: Hodgkin lymphoma. J Clin Invest 2012, 122(10):3439-3447.

61. Kuppers R: New insights in the biology of Hodgkin lymphoma. Hematology Am Soc Hematol Educ Program 2012, 2012:328-334.

62. Thomas RM: Hodgkin's lymphoma presenting as an abscess in thyroid gland. Indian J Pathol Microbiol 2012, 55(1):122-124.

63. Raemaekers JM, van der Maazen RW: Hodgkin's lymphoma: news from an old disease. Neth J Med 2008, 66(11):457-466.

64. Barros MH, Vera-Lozada G, Soares FA, Niedobitek G, Hassan R: Tumor microenvironment composition in pediatric classical Hodgkin lymphoma is modulated by age and Epstein-Barr virus infection. Int J Cancer 2012, 131(5):1142-1152.

doi:10.1186/1746-1596-8-116

Cite this article as: Szczepanek-Parulska et al.: Thyroid nodule as a first manifestation of Hodgkin lymphoma-report of two cases and literature review. Diagnostic Pathology 2013 8:116.

\section{Submit your next manuscript to BioMed Central and take full advantage of:}

- Convenient online submission

- Thorough peer review

- No space constraints or color figure charges

- Immediate publication on acceptance

- Inclusion in PubMed, CAS, Scopus and Google Scholar

- Research which is freely available for redistribution 